\title{
A Meta-Analysis of the Decline in the Labor Force Participation Rate
}

\author{
Ananth Seshadri
}




\title{
A Meta-Analysis of the Decline in the Labor Force Participation Rate
}

\author{
Ananth Seshadri \\ University of Wisconsin-Madison \& NBER
}

July 2018

\author{
Michigan Retirement Research Center \\ University of Michigan \\ P.O. Box 1248 \\ Ann Arbor, MI 48104 \\ www.mrrc.isr.umich.edu \\ (734) 615-0422
}

\section{Acknowledgements}

The research reported herein was performed pursuant to a grant from the U.S. Social Security Administration (SSA) funded as part of the Retirement Research Consortium through the University of Michigan Retirement Research Center Award RRC08098401-10. The opinions and conclusions expressed are solely those of the author(s) and do not represent the opinions or policy of SSA or any agency of the federal government. Neither the United States government nor any agency thereof, nor any of their employees, makes any warranty, express or implied, or assumes any legal liability or responsibility for the accuracy, completeness, or usefulness of the contents of this report. Reference herein to any specific commercial product, process or service by trade name, trademark, manufacturer, or otherwise does not necessarily constitute or imply endorsement, recommendation or favoring by the United States government or any agency thereof.

\section{Regents of the University of Michigan}

Michael J. Behm, Grand Blanc; Mark J. Bernstein, Ann Arbor; Shauna Ryder Diggs, Grosse Pointe; Denise Ilitch, Bingham Farms; Andrea Fischer Newman, Ann Arbor; Andrew C. Richner, Grosse Pointe Park; Ron Weiser, Ann Arbor; Katherine E. White, Ann Arbor; Mark S. Schlissel, ex officio 


\title{
A Meta-Analysis of the Decline in the Labor Force Participation Rate
}

\begin{abstract}
This project explores the causes behind the recent decline in the Labor Force Participation (LFP) rate. The analysis examines the evolution of the LFP rate for different demographic groups to gauge the effect of demographic changes. An integral part of the project is an investigation of the flows of workers into and out of the labor force to determine whether the LFP rate has been declining because more workers are leaving or because fewer workers are entering the labor market. The project also studies the evolution of wages and finds that the decline in the LFP rate is often accompanied by a declining real wage, which is indicative of the relative importance of demand versus supply factors.
\end{abstract}

\section{Citation}

Seshadri, Ananth. 2018. "A Meta-Analysis of the Decline in the Labor Force Participation Rate.” Ann Arbor MI: University of Michigan Retirement Research Center (MRRC) Working Paper, WP 2018-381. http://www.mrrc.isr.umich.edu/publications/papers/pdf/wp381.pdf/

\section{Author's acknowledgements}

I am indebted to Junjie Guo and Nick Tenev for expert research assistance. The collection of data used in this study was partly supported by the National Institutes of Health under grant number R01 HD069609 and R01 AG040213, and the National Science Foundation under award numbers SES 1157698 and 1623684. 


\section{Introduction}

The U.S. labor force participation (LFP) rate, which measures the fraction of the population $^{1}$ that are either employed or unemployed but actively looking for a job, peaked at 67.3 percent in early 2000 after increasing for about 40 years. Since then, the LFP rate has been declining for most of this century. In particular, it declined to about 66 percent by the end of 2004, remained roughly flat for longer than two years until the start of the Great Recession in the second half of 2007, and then declined to 62.4 percent in September 2015. The LFP rate has remained slightly below 63 percent in the last two years. A closer look at the LFP rate by age, gender, and education reveals that it declined for most of the demographic groups (Hipple 2016).

The decline in the LFP rate has attracted a lot of attention with many explanations proposed. Some examples are the aging of the population, the increase in school enrollment among the youth, the increase in the number of individuals with mental and physical health issues (Krueger 2017), the rise in incarceration and criminal records, ${ }^{2}$ the stagnation of real wage for low-skilled workers and the rising wage inequality (Council of Economic Advisers 2016), and technological changes that may have either reduced the demand for labor (through, for example, the automation of routine tasks and the use of robots. See Acemoglu and Restrepo 2017) or raised the value of leisure (through, for example, the creation of video games—see Aguiar et al. 2017).

While each of the proposed explanations may contribute to the recent decline in the LFPR, their relative importance is not well understood. This project attempts to fill this gap.

\footnotetext{
${ }^{1}$ The population referenced here includes residents of the 50 states and District of Columbia who are at least 16 years old and are not active duty members of the armed forces or living in institutions (e.g., nursing homes, prisons).

${ }^{2}$ While incarcerated persons are not included in the calculation of the labor force, there is evidence (e.g., MuellerSmith 2015) that past spells of incarceration affect labor market outcomes.
} 
We examine the evolution of LFP rate for different demographic groups to gauge the effect of demographic changes. We estimate the transition rates across different labor market statuses to see whether more workers are leaving the labor force or fewer workers are entering the labor force. We also use wage data to get a sense of the relative importance of demand and supply factors. Overall, we find that roughly half of the decline in labor force participation is attributable to demographic shifts, but that labor force participation within most demographic groups has been continuously declining. Disability is an increasingly common impediment to work, but wage incentives also play a role, as declines in labor force participation seem to be associated with weakening wage incentives to enter or re-enter the labor force.

\section{Data}

Before proceeding with the analysis, this section briefly describes the datasets used, and the advantages and disadvantages of each.

The Current Population Survey (CPS) is conducted monthly by the Bureau of Labor Statistics and provides the most widely-cited official measure of labor force participation. Its main advantages are frequency and sample size: around 60,000 households are surveyed. Owing to its size, this data set will be used when possible. However, the set of questions asked in the CPS is limited, and the same respondents are not followed over long periods of time. ${ }^{3}$

The Panel Study of Income Dynamics (PSID) has tracked a representative cohort of respondents and their offspring since its inception in 1968. While the PSID affords a smaller sample of individuals than the CPS, it provides more detailed information about respondents (in particular, health), and has the additional advantage of following the same people over time.

\footnotetext{
${ }^{3}$ For more information on the CPS, see https://www.census.gov/programs-surveys/cps/technicaldocumentation/methodology.html
} 
However, the latest wave available for the PSID is 2015, which precludes the use of this dataset for very recent analysis. In the sections that follow, the text will note which data set is used for which analysis.

\section{Statistical Decomposition}

We start by categorizing the population into different demographic groups by age ${ }^{4}$ and sex, and quantifying the contribution of each group to the overall decline in the LFP rate. As each group is likely to be affected differently by the explanations mentioned above, the relative contribution of each demographic group to the overall decline in the LFP rate serves as an indication of the relative importance of each explanation.

The LFP rate in any period can be expressed as the average of the LFP rate of each demographic group $L F P_{i t}$ weighted by its share in the population $\mu_{i t}$

$$
L F P_{t}=\sum_{i}\left(\mu_{i t} L F P_{i t}\right)
$$

Accordingly, the difference in the LFP rate between any two periods can be decomposed into two components: (1) changes in the distribution of population across demographic groups, $\mu_{i t}-\mu_{i s}$, and (2) changes in the LFP rate of each demographic group, $L F P_{i t}-L F P_{i s}$, as follows

$$
L F P_{t}-L F P_{s}=\sum_{i}\left(\left(\mu_{i t}-\mu_{i s}\right) L F P_{i t}+\mu_{i s}\left(L F P_{i t}-L F P_{i s}\right)\right)
$$

From this decomposition, we calculate the contribution of demographic shifts $\sum_{i}\left(\left(\mu_{i t}-\right.\right.$ $\left.\left.\mu_{i s}\right) L F P_{i t}\right)$, as well as the behavioral change in each demographic group $\mu_{i s}\left(L F P_{i t}-L F P_{i s}\right)$ to the overall change in the LFP rate between the two periods $\left(L F P_{t}-L F P_{S}\right)$. As demographic

\footnotetext{
${ }^{4}$ Individuals 80 and older are grouped together, as exact ages for elderly respondents are not available for the whole sample.
} 
shifts over time are mechanical, we will focus on the behavioral changes within each group in the following.

Given the evolution of the LFP rate in the last two decades, we perform the decomposition four times: (1) for the 1990s, (2) between 2000 and the start of the Great Recession in 2007, (3) between 2008 and 2015, and (4) for the last two years. The comparison between (1) and (2) will be informative as to whether there are behavioral changes around 2000, and if so, their importance for the changing behavior of the overall LFP rate. The comparison among the last three decompositions will be informative of whether the Great Recession has any temporary and long run effects on the LFP of each demographic group. Table 1 gives the results of the decomposition, using data from the Current Population Survey (CPS).

\section{Table 1: Decomposition of changes in labor force participation}

\begin{tabular}{|c|c|c|c|c|}
\hline Year & $\begin{array}{c}\text { Labor force } \\
\text { participation } \\
(\%)^{5}\end{array}$ & Change (pp) & $\begin{array}{c}\text { Demographic } \\
\text { contribution (pp) }\end{array}$ & $\begin{array}{c}\text { Behavioral } \\
\text { contribution (pp) }\end{array}$ \\
\hline 1990 & 66.53 & & & \\
\hline 2000 & 67.07 & 0.55 & 0.85 & -0.31 \\
\hline 2007 & 66.04 & -1.03 & -0.61 & -0.42 \\
\hline 2015 & 62.65 & -3.39 & -1.61 & -1.77 \\
\hline 2017 & 62.85 & 0.20 & 0.72 & -0.52 \\
\hline
\end{tabular}

5 Labor force is computed from CPS data provided by IPUMS (Ruggles et al. 2017), weighted using the final person-level weight for 1990 and composite weight thereafter, to match published Bureau of Labor Statistics figures. 
Figure 1: Decomposition of changes in labor force participation

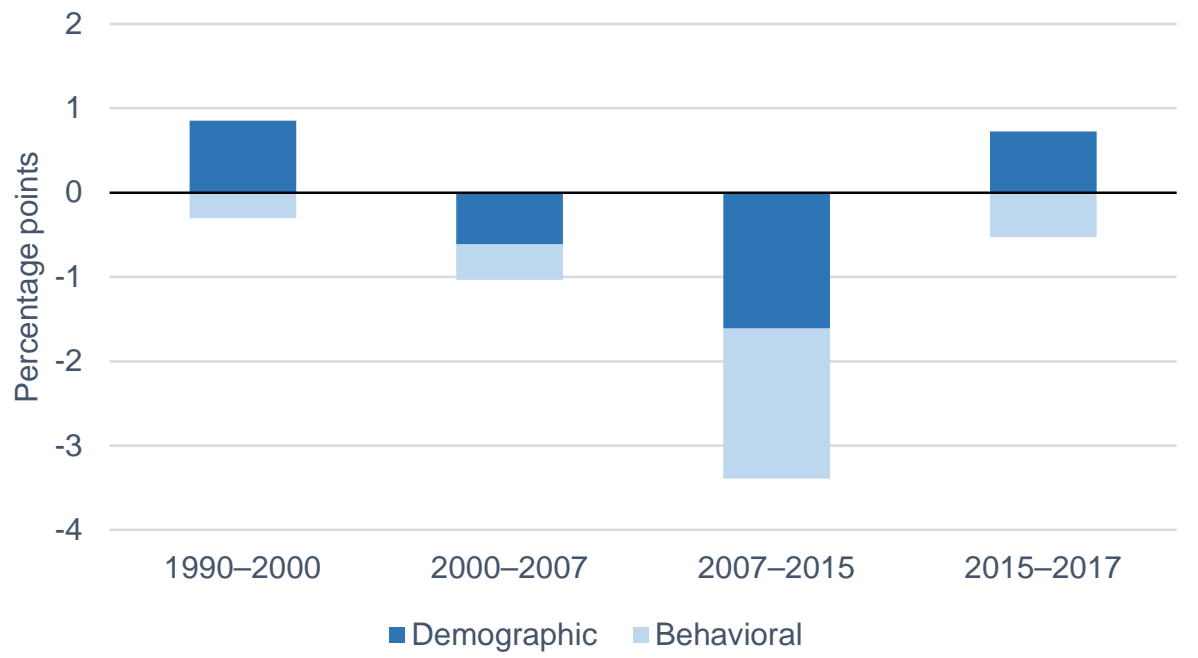

For all the time periods considered, the behavioral contribution is negative, signaling that on average, labor force participation within demographic groups has been continuously declining. The increases in overall participation from 1990 to 2000 and from 2015 to 2017 can be entirely explained by demographic shifts. Between 2000 and 2015, the behavioral and demographic contributions to the decline in overall labor force participation were comparable. The lion's share of this overall decline—-more than 3 percentage points total—occurred following the 2008 recession.

What can account for the participation shifts within these demographic groups? One potential cause is increasing enrollment in school, which often precludes labor force participation. Enrollment has indeed increased since 1990 (Figure 2), but the labor force participation of enrolled students has declined since 2000, counteracting the effect on the overall participation rate. 
Figure 2: Enrollment and labor force participation

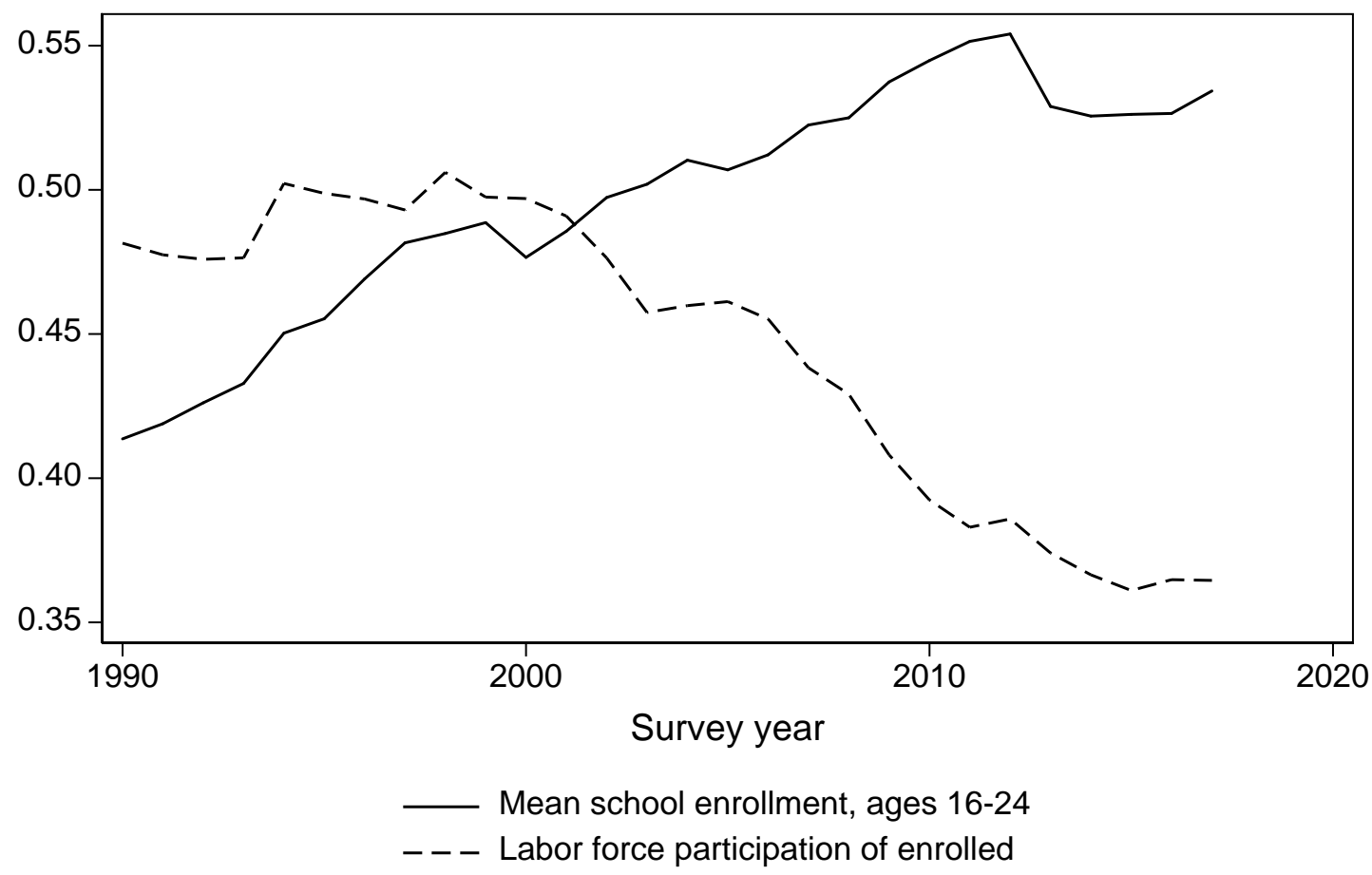

Workers may also remain outside the labor force if they are disabled. Beginning in 2008, the CPS started asking respondents about various types of difficulties: hearing difficulty, vision difficulty, difficulty remembering, physical difficulty, disability limiting mobility, and personal care limitation. Over the limited timespan for which data are available, the fraction of workers reporting any difficulty (of those listed above) has increased only modestly (Figure 3). The labor force participation of those reporting difficulty has broadly declined. 
Figure 3: Disability and labor force participation

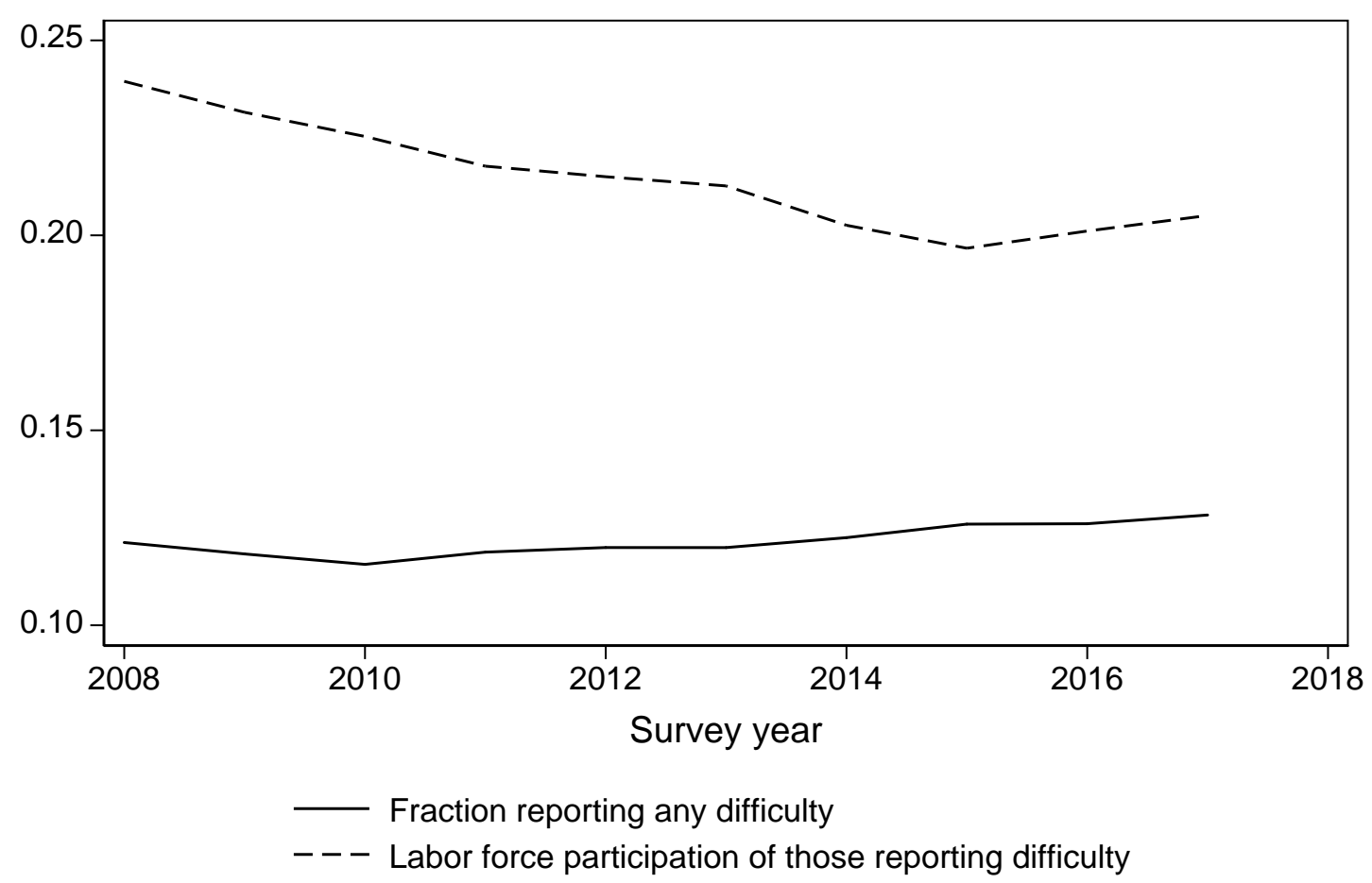

The PSID has fewer respondents but asks more detailed questions about respondents’ health, and has been doing so for longer than the CPS. In particular, the PSID asks respondents if they experience disability that limits their ability to work. ${ }^{6}$ Figure 4 shows that work-limiting disability has increased over time for all but, perhaps, some of the youngest workers. Disability does, indeed, seem to prevent more and more people from working.

\footnotetext{
${ }^{6}$ Specifically, respondents are asked if they "have any physical or nervous condition that limits the type of work or the amount of work [they] can do?" Those who answer yes are asked "For work you can do, how much does it limit the amount of work you can do--a lot, somewhat, or just a little?” We code responses "A lot" and "Somewhat" as indicating a work-limiting disability.
} 
Figure 4: Work-limiting disability by age

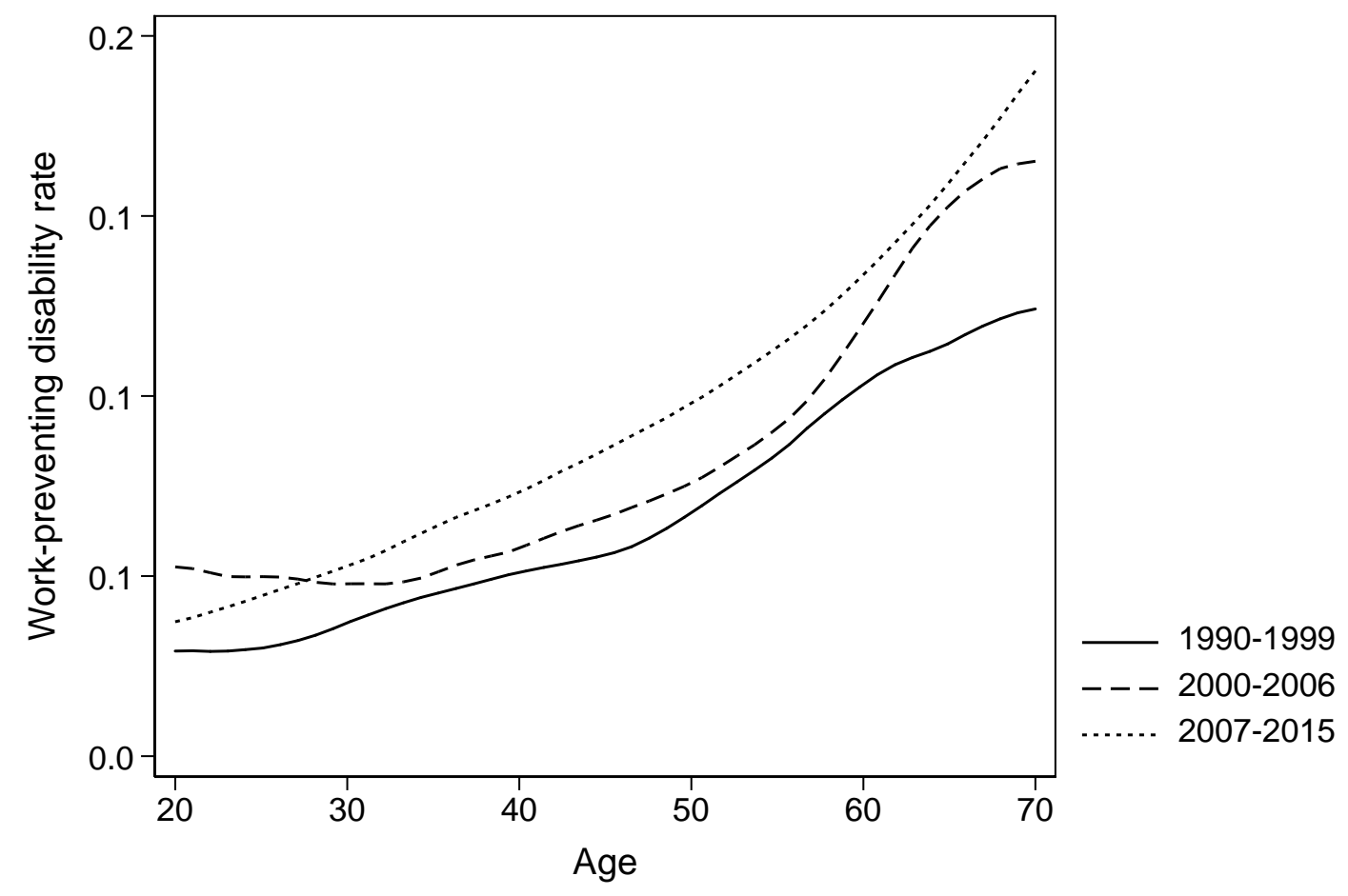

Note: Each line displays the result of a kernel-weighted local polynomial regression.

\section{Transitions into and out of Labor Force}

Given the relative importance of behavioral changes for each demographic group recovered from the statistical decomposition, we proceed to analyze the causes behind the behavioral change for each group and investigate whether these behavioral shifts over time are correlated across demographic groups. A lack of correlation suggests that different explanations may be needed for different demographic groups. Otherwise, common factors affecting all groups may be required.

We will start by constructing the transition rates among the three labor market statuses (employed: E; unemployed: U; out of labor force: $\mathrm{N}$ ) and track their behaviors over time. Let 
$\pi_{A B}^{i t}$ be the transition rate between status $A$ and $B$ for demographic group $i$ at time $t$, the instantaneous change in the LFP rate at time $t, \Delta L F P_{i t}$, can be expressed as

$$
\Delta L F P_{i t}=\left(\pi_{N E}^{i t}+\pi_{N U}^{i t}\right) N_{i t}-\left(\pi_{E N}^{i t} E_{i t}+\pi_{U N}^{i t} U_{i t}\right)
$$

where, abusing notations a little bit, we use $\mathrm{E}, \mathrm{U}$, and $\mathrm{N}$ to represent both the three labor market statuses and the share of the population in those statuses.

A decline in the LFP rate occurs when the second term on the right-hand side is larger than the first term. That is, more workers are exiting from either employment (E) or unemployment (U) into nonparticipation (N) than entering the labor force from nonparticipation. A decline in LFP is associated with an increase in $N$ because, by definition, $N=1-L F P=1-(E+U)$. As a result, in order for the LFP rate to keep decreasing, we need $\pi_{N E}^{i t}+\pi_{N U}^{i t}$ to decrease relative to $\pi_{E N}^{i t}$ and $\pi_{U N}^{i t}$

It is interesting to know, for each demographic group, which of the four transition rates contributes to the majority of the recent decline in the LFP rate. While an increase in the unemployment-to-nonparticipation rate $\pi_{U N}^{i t}$ and a decrease in the nonparticipation-toemployment rate $\pi_{N E}^{i t}$ could both result in a decrease in the LFP rate, they have potentially different implications for the labor market. For example, an increase in $\pi_{U N}^{i t}$ could imply that more workers are discouraged away from the labor market due to a low job-finding rate, a decrease in $\pi_{N E}^{i t}$ is consistent with a rise in the value of leisure. The policy implications from these two cases are certainly different.

Following Shimer (2012), we can estimate the different transition rates for each demographic group in each period using data from the Current Population Survey (CPS). With 
the estimated transition rates, we can investigate whether the same transition rate is responsible for the decline in LFP rate for all demographic groups.

Specifically, let $\pi^{i t}$ be the $3 \times 3$ matrix containing the transition rates between states $\{E, U, N\}$ in continuous time. Shimer (2012) demonstrates that this can be computed from monthly CPS data as follows. First, let $n^{i t}$ be the analogous month-to-month transition rates for demographic group $i$. This is not necessarily equal to $\pi^{i t}$; note that for example the upper-left entry of $n^{i t}$ (the chance of being employed given employment the previous month) will include the possibility of losing one's job but finding new employment in less than a month. The continuous time transition matrix can, however, be computed from the month-to-month transition matrix as follows:

$$
\pi^{i t}=P^{i t} * \tilde{\mu}^{i t} *\left(P^{i t}\right)^{-1} .
$$

Here $P^{i t}$ is the $3 \times 3$ matrix of eigenvectors of $n^{i t}$, and $\tilde{\mu}^{i t}$ is a $3 \times 3$ matrix containing the log eigenvalues of $n^{i t}$ along the diagonal; for further details see Shimer (2012). For this section's analysis, we bin individuals into four age groups: younger than 30,30 to 44, 45 to 59, and older than 60 . 
Figure 5: Transitions to employment from outside labor force

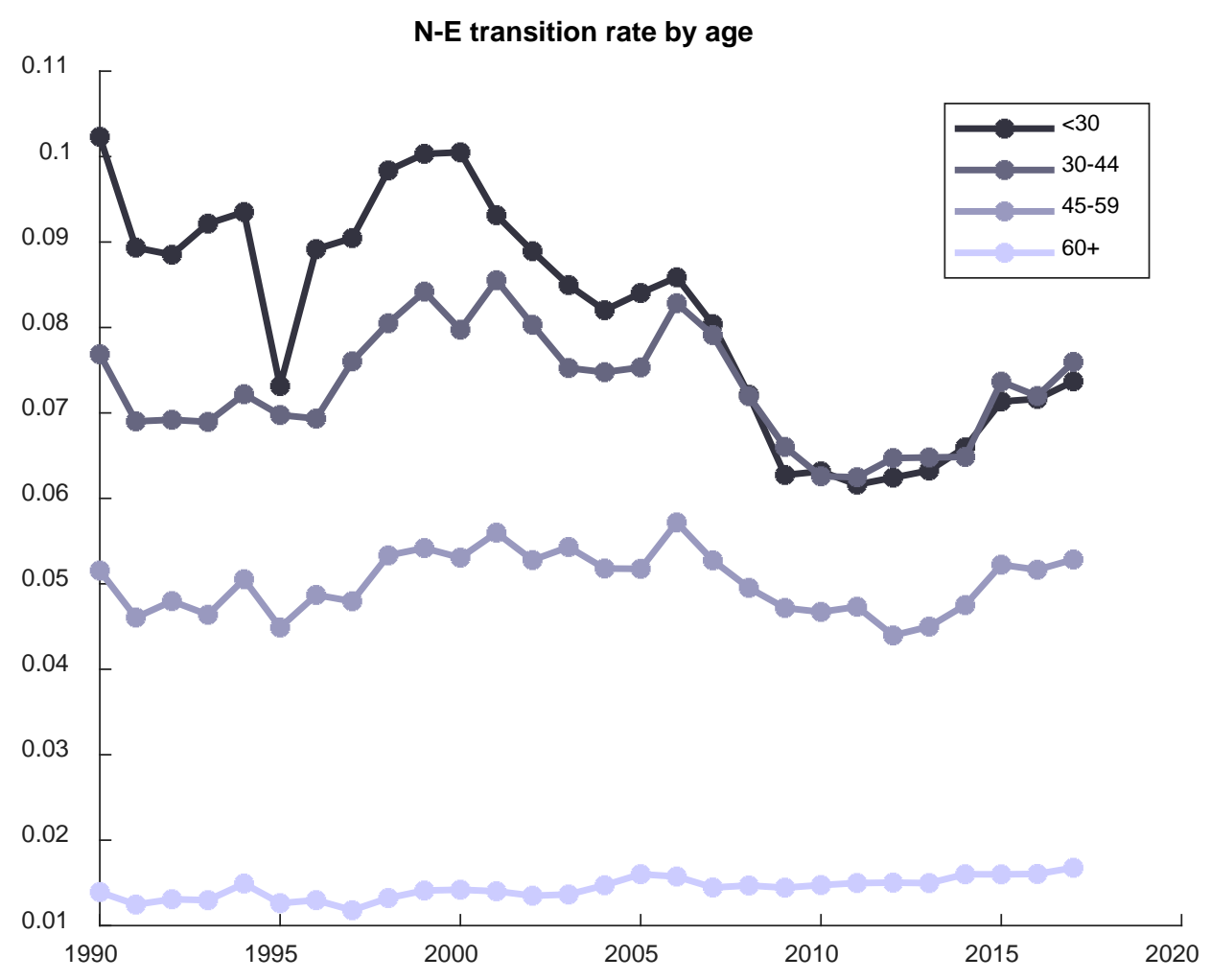

Figure 5 shows the transition rates into the labor force to employment. Figure 5:

Transitions to employment from outside labor forceFigure 5 shows a marked decline in transitions to employment following the 2008 recession for all but the oldest workers, from which none of these groups has yet recovered. The data are noisy, but the youngest group of workers seems to have experienced a secular decline in transitions into the labor force, consistent with an increased value of leisure for these workers. 
Figure 6: Transitions to unemployment from outside the labor force

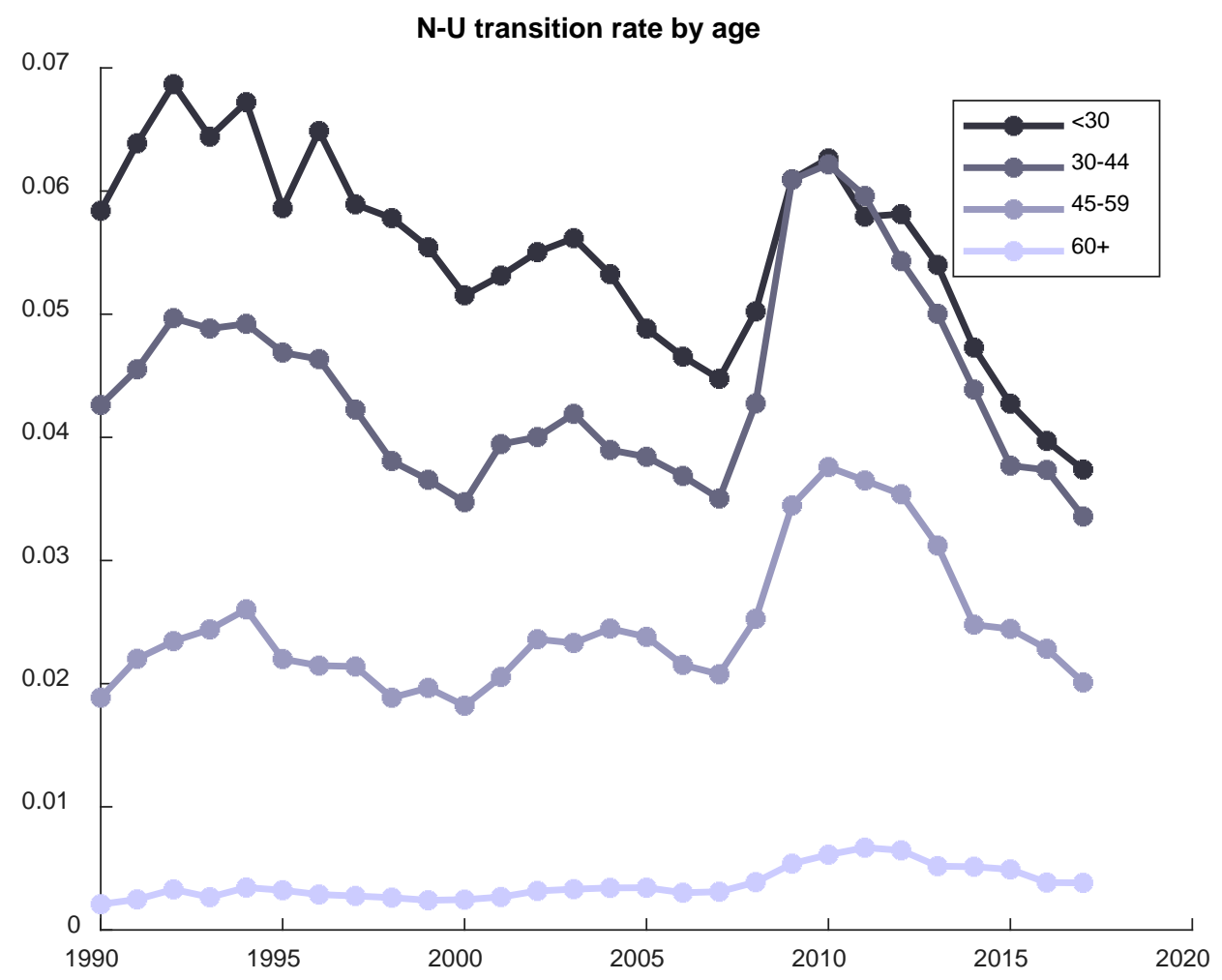

Figure 6 shows how often workers who are not in the labor force transition to unemployment — an active search for work. Notable in Figure 6 is the increase in those looking for work during and following the 2008 recession. This may reflect the fact that as wage earners lost their jobs in the downturn, their adult dependents may have had to look for work themselves. This uptick seems to have been temporary, as the transition rates from out of the labor force to unemployment have returned to prerecession levels. In particular, the rate at which workers younger than 30 who are not in the labor force begin looking for work has resumed its secular trend lower and fallen to its lowest level in decades. 
Figure 7: Transitions out of the labor force from employment

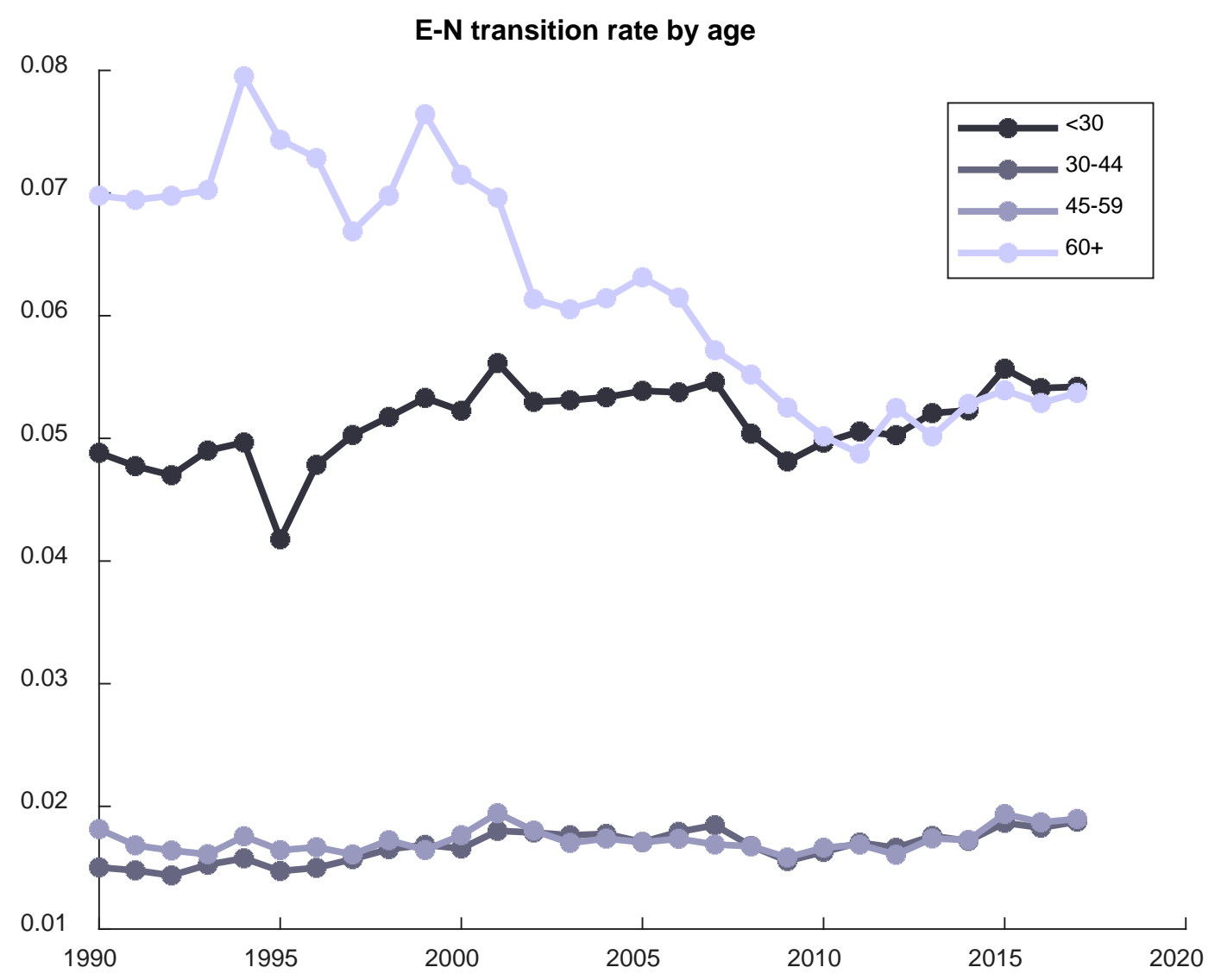

Figure 7 and Figure 8 show the rates of transition out of the labor force from employment and unemployment, respectively. Figure 7 shows a secular decline in employed older workers leaving the labor force, as people choose to retire later and later. For the youngest group of workers, however, the trend is the opposite (albeit much more moderate) - more employed workers have been leaving the labor force, save a dip following the recession. Employed workers aged 30 to 59 are unsurprisingly unlikely to quit the labor force, and this has not changed much over the sample period. 
Figure 8: Transitions out of the labor force from unemployment

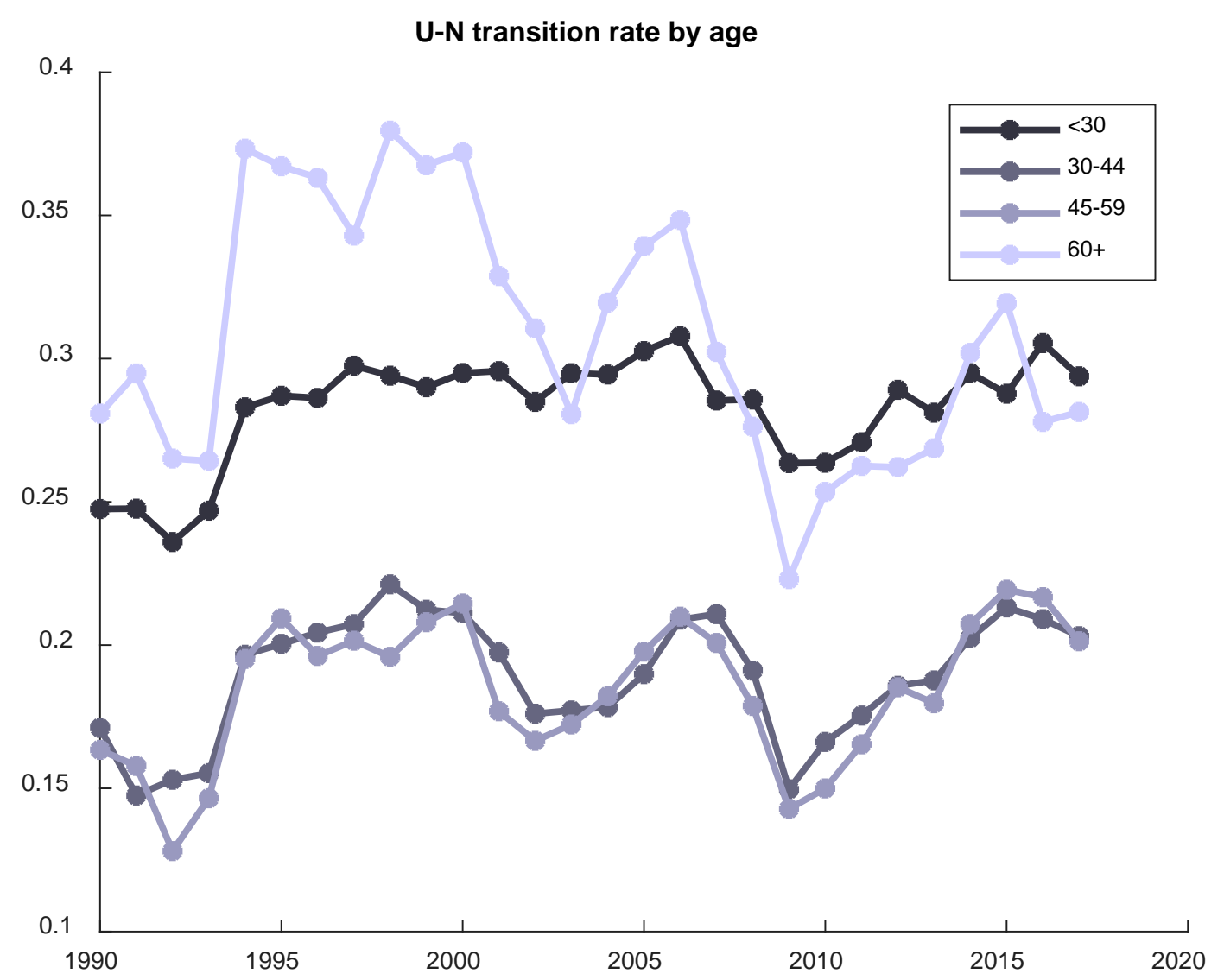

Transitions out of the labor force from unemployment (Figure 8) are more volatile and thus harder to interpret. But for the youngest group of workers, the trend appears similar to that for employed workers. Overall, therefore, young workers seem to be both more likely to leave the labor force and less likely to enter or return. The increasing disengagement of young workers with the labor force is of particular concern, as the consequences of human capital development are further-reaching than they would be later in the life cycle. 


\section{Separating Demand and Supply Factors Using Wage Data}

Most studies on the recent decline in the LFP rate do not look at wage data. We argue that wage data are useful in distinguishing different explanations.

Broadly speaking, explanations proposed in the literature fall into two categories, demand and supply. While demand factors such as the automation of routine jobs and the use of robots will reduce the LFP rate and wage at the same time, supply side factors that lead to a decrease in the LFP rate are likely to result in an increase in wages. For example, if the LFP rate decreases due to an increase in the value of leisure through the creation of video games, it is likely to work through a higher reservation wage. Similarly, a decrease in the LFP rate due to more people with mental and health problems will result in a higher wage as the labor supply curve shifts to the left. As a result, we use wage data to infer whether demand or supply factors are more important for the recent decline in the LFP rate.

\section{Coevolution of wages and LFP}

In particular, for each demographic group, we track the evolution of wage and correlate it to the evolution of the LFP rate over time. In addition, looking across groups, we investigate whether the growth rate of wages is related to the decline of the LFP rate.

Specifically, let $w_{i t}$ be the average wage of demographic group $i$ at time $t$. Within each group, we can use the sign of $\operatorname{Cov}\left(w_{i t}, L F P_{i t}\right)$ as an indicator for whether demand or supply factors are more important for the decline in the LFP rate for this group.

Since these calculations only require data on average wages and labor force participation within demographic groups, we will here again use data from the CPS, which have the benefits of large sample size and representativeness within year. We use log hourly wages, which are 
deflated using the Consumer Price Index Research Series (CPI-U-RS) from the Bureau of Labor Statistics.

Table 2 gives, by age group and time period, the covariance over time (the frequency is monthly) between average hourly wages and average labor force participation for women; Table 3 gives the analogous figures for men.

\section{Table 2: Covariance between wages and LFP of women}

\begin{tabular}{|c|c|c|c|c|}
\hline \multirow[b]{2}{*}{ Years } & \multicolumn{4}{|c|}{$\begin{array}{c}\operatorname{Cov}\left(w_{i t}, L F P_{i t}\right), \text { Women } \\
\text { Age }\end{array}$} \\
\hline & $<30$ & 30 to 44 & 45 to 59 & $60+$ \\
\hline 1990 to 1999 & -0.005 & 0.465 & 0.840 & 0.308 \\
\hline 2000 to 2006 & 0.067 & -0.467 & 0.233 & 0.706 \\
\hline 2007 to 2014 & 0.099 & 0.286 & 0.554 & 0.591 \\
\hline 2015 to 2017 & 0.167 & 0.503 & 0.247 & -0.067 \\
\hline
\end{tabular}

Table 3: Covariance between wages and LFP of men

\begin{tabular}{|c|c|c|c|c|}
\hline \multirow[b]{2}{*}{ Years } & \multicolumn{4}{|c|}{$\begin{array}{c}\operatorname{Cov}\left(w_{i t}, L F P_{i t}\right), \text { Men } \\
\text { Age }\end{array}$} \\
\hline & $<30$ & 30 to 44 & 45 to 59 & $60+$ \\
\hline 1990 to 1999 & -0.202 & 0.209 & -0.137 & -0.062 \\
\hline 2000 to 2006 & 0.120 & 0.348 & 0.127 & 0.322 \\
\hline 2007 to 2014 & 0.351 & 0.695 & 0.640 & 0.387 \\
\hline 2015 to 2017 & 0.160 & 0.455 & 0.500 & -0.063 \\
\hline
\end{tabular}

For convenience, negative covariances are colored red. These signal groups in which, for the indicated time period, average log wages grew while LFP declined (or vice versa). For most demographic groups, however, wages and labor force participation tended to vary together from 
month to month. This suggests that declines in wages may have reduced the incentives to pursue employment, resulting in lower labor force participation.

Across groups, we can use $\operatorname{Cov}\left(\Delta \log w_{i t}, \Delta L F P_{i t}\right)$ as an indicator for whether demand or supply factors are more important for the between-group variation in the decline of the LFP rate. Table 4 gives the results for each time period.

\section{Table 4: Covariance between growth in wages and LFP across groups}

\begin{tabular}{c|c} 
Years & $\operatorname{Cov}\left(\Delta \log w_{i t}, \Delta L F P_{i t}\right)$ \\
\hline 1990 to 2000 & 0.000861 \\
2000 to 2007 & 0.001019 \\
2007 to 2015 & 0.000707 \\
2015 to 2017 & -0.000057 \\
\hline
\end{tabular}

For this table, a group is considered to be all people of the same age (in years) and sex. So $\Delta \log w_{i t}$ is, for example, the difference in average log wages for group $i$ between (in the first row) 1990 and 2000, and similarly for LFP. The covariance across groups is weighted by the groups' populations in the base year.

The across-groups covariance between growth in wages and growth in LFP is positive for all periods except 2015 —2017 (and even then, the negative correlation is an order of magnitude lower). In general, demographic groups with declines in wages tended to lower their labor market participation, a signal that workers left the labor market as incentives to work declined. This is consistent with the evidence from within-group variation: Declines in labor force participation may be, in part, attributable to stagnation in wages. 


\section{Starting/exiting wages}

It is interesting to consider specifically starting wages $w_{i t}^{S}$ received by workers who were previously unemployed or out of the labor force, as well as the last wage $w_{i t}^{E}$ received by workers who exit the labor force directly from employment, because these are the relevant margins that are directly related to the LFP decisions. In particular, we would expect a decline in $w_{i t}^{S}$ if demand factors are more important, and an increase in $w_{i t}^{E}$ if supply factors are more important.

For this analysis, we use data from the PSID. The PSID does in certain years ask for respondents' starting wages at their current jobs, as well as their final wages at their previous jobs. However, the sample is too small to draw inference about changes over time. Instead, we look at the log wage of workers who reported undergoing a spell of unemployment in the past year, and compare it to their last reported ${ }^{7} \log$ wage. This does not perfectly capture starting wage or exiting wage. And for workers currently out of the labor force, it does not guarantee that they did not experience a spell of unemployment in between working and leaving the labor force. However, it should still be indicative of the cost of undergoing a spell of unemployment, and the relevant wage incentives surrounding labor force entry and exit. All wages are deflated using the CPI-U-RS.

\footnotetext{
${ }^{7}$ Through 1997, the previous wage will be the previous year's, as respondents were interviewed annually. From 1999 onward, the previous wage will be from two years prior, as the PSID switched to only interviewing respondents every other year.
} 
Figure 9: Starting wages and exit wages for workers leaving the labor force

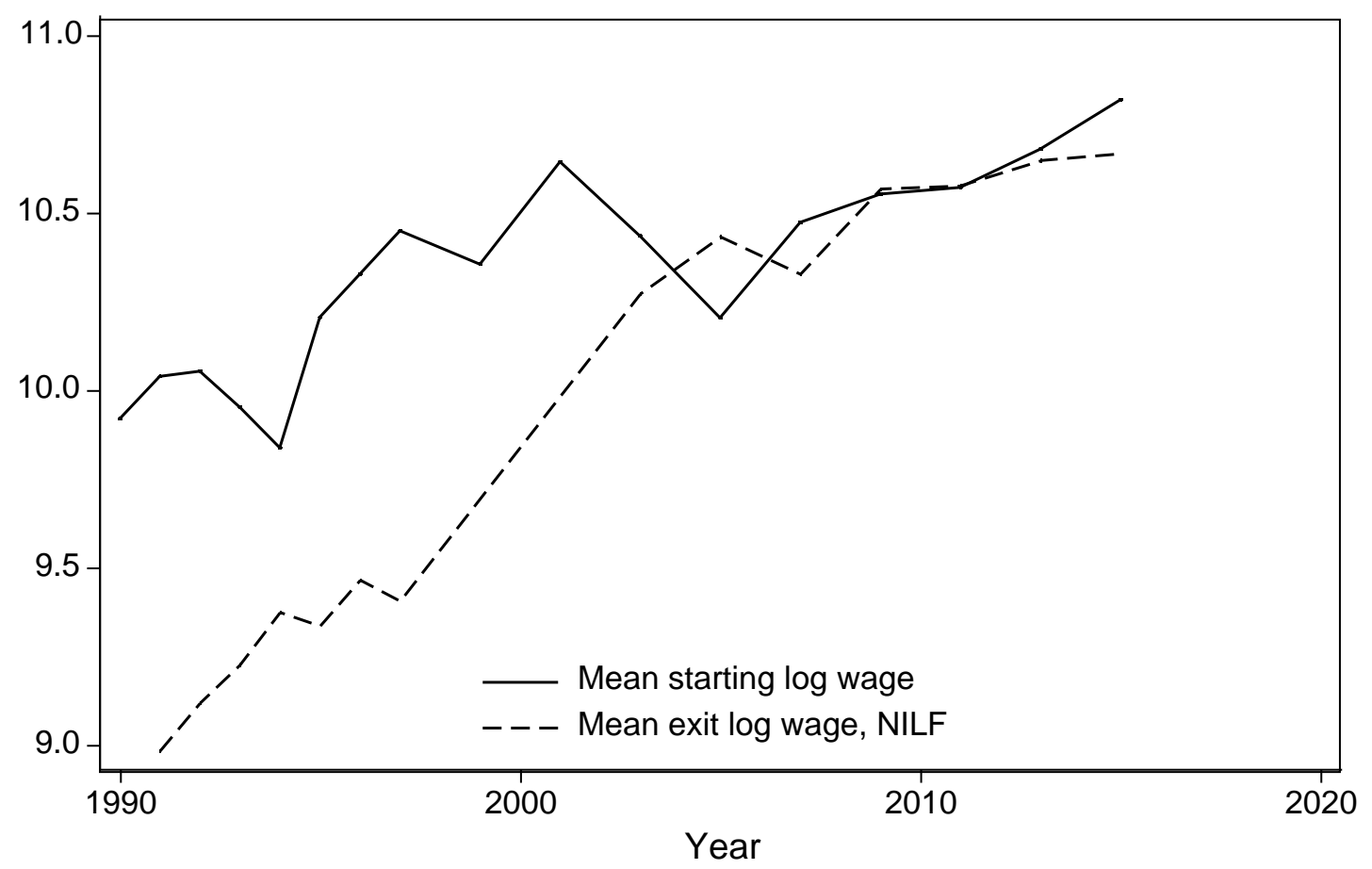

Figure 9 gives the average log starting wage as well as the average log previous wage for workers who are not in the labor force. The growth of starting wage of workers entering or reentering the labor force has lagged behind mean exit wages over the sample period. This suggests that even if incentives to remain in the labor force remain strong, the incentives to rejoin the labor force may be declining. As noted, this analysis is imperfect as we cannot be sure that the workers leaving the labor force are doing so directly from employment, or that the mean starting wage is truly representative for the type of worker choosing to leave the labor force from employment.

We also examine the evolution of the difference between the starting wage and the last wage for workers coming out of a nonemployment spell, $\log w_{i t}^{S}-\log w_{i t}^{E}$, as well as the returns 
to continued employment. Both of them measure the wage loss from employment gaps. Other things equal, the larger is this loss, the less likely a worker will return to the labor force.

Table 5 shows, by time period, the average change in log wages for workers who reported undergoing a spell of unemployment. The standard deviations are too large to draw firm conclusions, but the point estimates following 2000 are larger than the one for the 1990s, consistent with an increased wage penalty for unemployment spells.

Table 5: Change in wages following unemployment

\begin{tabular}{c|cc}
\multicolumn{1}{c}{ Years } & \multicolumn{1}{c}{$\begin{array}{c}\text { Change in log } \\
\text { wages following } \\
\text { unemployment }\end{array}$} & $\begin{array}{c}\text { Standard } \\
\text { deviation }\end{array}$ \\
\hline $\mathbf{1 9 9 0}$ to 1999 & -0.044 & 0.982 \\
$\mathbf{2 0 0 0}$ to 2006 & -0.156 & 1.198 \\
$\mathbf{2 0 0 7}$ to 2015 & -0.107 & 1.289 \\
\hline
\end{tabular}

Return to continued employment

We estimate the return to continued employment using the following equation

$$
\log w_{i t}=X_{i t} \beta_{t}+\gamma_{T} E_{i t}+\varepsilon_{i t} .
$$

Here $X_{i t}$ is a vector of individual characteristics including an individual fixed effect (which absorbs characteristics that don't change over the sample period, such as gender, race, and education), state fixed effects, a year fixed effect, and the total work experience of individual $i$ at time $t . E_{i t}$ is the length of the current employment spell, and $\varepsilon_{i t}$ is the error term. In this specification, $\gamma_{t}$ is a measure of the return to continued employment in period time $T$. 
We use panel data from the PSID to estimate $\gamma_{t}$ for each period. An increase in $\gamma_{t}$ over time is consistent with an increase in the cost of employment gaps, which is likely to discourage workers out of the labor force. We will investigate this by studying the joint evolution of $\gamma_{t}$ and $L F P_{t}$ over time.

Figure 10: Estimated return to continued employment

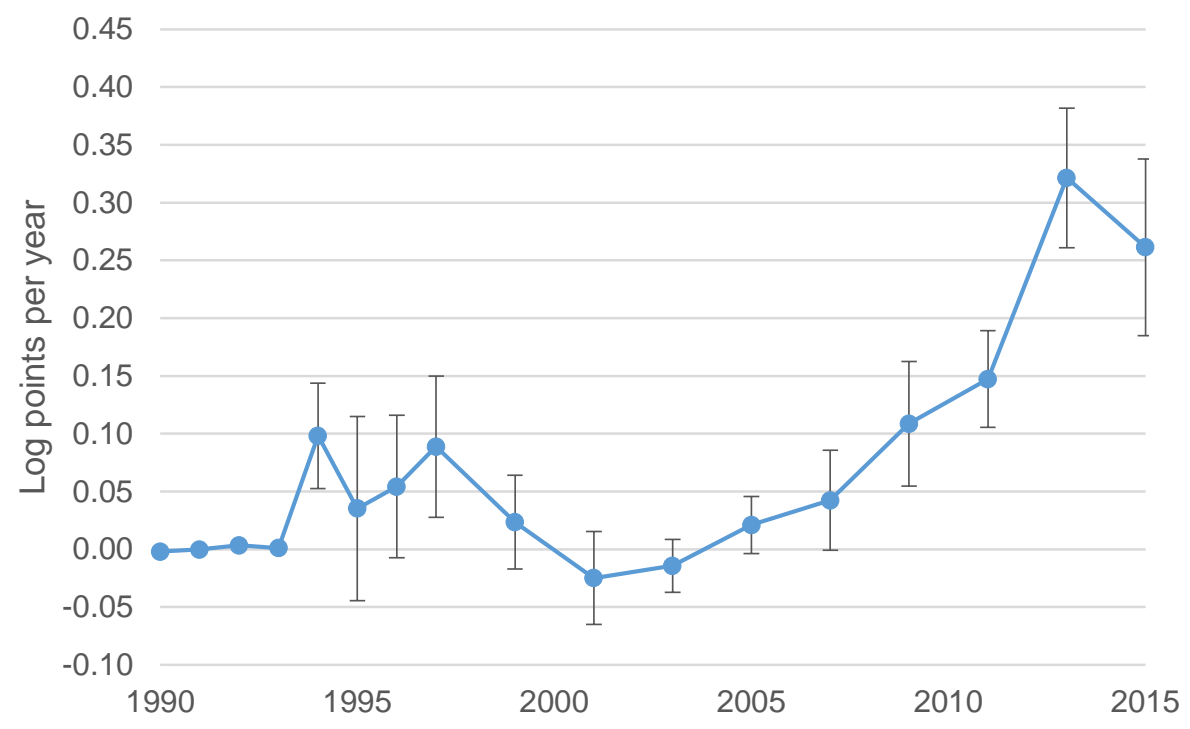

The main takeaway is that the association between continued employment and wages has grown substantially, especially following the 2008 recession. So relative to continued employment, this suggests a growing penalty for time spent not working, which would discourage labor force participation.

Since the potential determinants we have studied are likely correlated with each other, and most of them are likely affected by other factors not considered in this project, this study may not be able to estimate the causal effect of each potential determinant. However, by relating the evolution of LFP rate to the evolution of most of its potential determinants, this study is informative as to which groups of factors are most likely to be the main drivers behind the recent 
decline in the LFP rate. The results of this section add an important nuance to the analysis of the previous section, demonstrating that the lack of wage growth associated with declining labor force participation may be explained in part by increasingly large wage penalties for unemployment spells.

\section{Discussion}

This paper decomposes the decline in labor force participation, and explores some evidence for why more workers are choosing not to seek employment. While roughly half of the decline in labor force participation since 2000 can be attributed to demographic shifts, participation within groups has continuously declined as well. Young workers in particular have been both less likely to enter the labor force and more likely to leave. Across the age spectrum, disability seems to be an increasingly common factor limiting work. Between and across demographic groups, we find evidence of covariation between wages and labor force participation, which is consistent with lagging wage growth discouraging workers from seeking employment. The association between wages and continued employment has been growing, suggesting increasing incentives to remain employed, but decreasing incentives to return to employment for those out of a job. So overall, much of the decline in labor force participation may be related to the wage incentives associated with participation and entry in particular. 


\section{References}

Acemoglu, Daron, and Pascual Restrepo. 2017. "Robots and Jobs: Evidence from US Labor Markets." NBER Working Papers 23285, National Bureau of Economic Research, Inc.

Aguiar, Mark, Mark Bils, Kerwin, Kofi Charles, and Erik Hurst. 2017. "Leisure Luxuries and the Labor Supply of Young Men." NBER Working Papers 23552, National Bureau of Economic Research, Inc.

Council of Economic Advisers. 2016. “The Long-Term Decline in Prime-Age Male Labor Force Participation.” U.S. President's Council of Economic Advisers.

Hipple, Steven. 2016. "Labor force participation: what has happened since the peak?" Monthly Labor Review, U.S. Bureau of Labor Statistics, September 2016.

Krueger, Alan B. 2017. "Where Have All the Workers Gone? An Inquiry into the Decline of the U.S. Labor Force Participation Rate.” Conference draft, Brookings Papers on Economic Activity.

Mueller-Smith, Michael. 2015. "The Criminal and Labor Market Impacts of Incarceration.” Working paper, University of Michigan.

Panel Study of Income Dynamics, public use dataset. 2018. Produced and distributed by the Survey Research Center, Institute for Social Research, University of Michigan, Ann Arbor, MI.

Ruggles, Steven, Katie Genadek, Ronald Goeken, Josiah Grover, and Matthew Sobek. 2017. Integrated Public Use Microdata Series: Version 7.0 [dataset]. Minneapolis: University of Minnesota, 2017. https://doi.org/10.18128/D010.V7.0.

Shimer, Robert. 2012. "Reassessing the Ins and Outs of Unemployment." Review of Economic Dynamics, Elsevier for the Society for Economic Dynamics, vol. 15(2), pages 127-148, April. 